\title{
Transport of larvae and detritus across the surf zone of a steep reflective pocket beach
}

\author{
Alan L. Shanks ${ }^{1, *}$, Jamie MacMahan ${ }^{2}$, Steven G. Morgan ${ }^{3}$, Ad J. H. M Reniers ${ }^{4}$, \\ Marley Jarvis ${ }^{1}$, Jenna Brown ${ }^{2}$, Atsushi Fujimura ${ }^{4}$, Chris Griesemer ${ }^{3}$ \\ ${ }^{1}$ Oregon Institute of Marine Biology, University of Oregon, PO Box 5389, Charleston, Oregon 97420, USA \\ ${ }^{2}$ Department of Oceanography, Naval Postgraduate School, 327c Spanagel Hall, Monterey, California 93943, USA \\ ${ }^{3}$ Bodega Marine Laboratory, Department of Environmental Science and Policy, University of California Davis, \\ 2099 Westside Dr., Bodega Bay, California 94923-0247, USA
}

${ }^{4}$ Department of Hydraulic Engineering, Delft University of Technology, Civil Engineering and Geosciences, Stevinweg 1 , 2628CN Delft, The Netherlands

\begin{abstract}
Larvae of many intertidal species develop offshore and must cross the surf zone to complete their onshore migration to adult habitats. Depending on hydrodynamics, the surf zone may limit this migration, especially on reflective rocky shores. As a logistically tractable analog of a rocky shore environment, we carried out a comprehensive biological and physical study of the hydrodynamics of a steep reflective sandy beach. Holoplankton and precompetent larval invertebrates were much less abundant within the surf zone than offshore, and their concentrations inside and outside the surf zone were not significantly correlated, suggesting that they were not entering the surf zone. Persistent offshore flow throughout the water column at the outer edge of the surf zone may prevent these organisms from entering the surf zone. In contrast, the concentrations of detritus and a competent larval invertebrate (i.e. cyprids), while also not significantly correlated with concentrations offshore, were frequently more concentrated in the surf zone than offshore. Within the surf zone, the concentration of detritus was significantly correlated with concentrations of competent larval invertebrates (barnacles, gastropods, polychaetes, and bopyrid amphipod) and organisms that may be associated with detritus (amphipods and harpacticoid copepods). These concentrations were significantly negatively correlated with average daily wave height. We hypothesize that detritus and larvae enter the surf zone near the bottom during calm wave conditions by a process of near-bottom streaming. Near-bottom streaming is associated with all surf zones and may be a general mechanism for onshore transport of larvae close to the coast.
\end{abstract}

KEY WORDS: Streaming - Cyprids - Competent larvae - Precompetent larvae - Detritus · Reflective beach $\cdot$ Cross-shore exchange

Resale or republication not permitted without written consent of the publisher

\section{INTRODUCTION}

Larval development of many intertidal fishes and invertebrates occurs in the coastal ocean. At the end of their development, these larvae must return to shore to settle into their adult habitat. The last stage in this shoreward migration is to enter and cross the surf zone. Strong swimming larvae may be able to swim across, but weak swimming larvae likely de- pend on surf zone exchange processes to transport them onshore. Thus, onshore migrations of all larvae should be facilitated when water in the surf zone is exchanged with adjacent water seaward of the surf zone, and reduced when this exchange is limited.

Surf zone hydrodynamics, in particular the exchange of water, varies with beach morphology and wave conditions. Beach morphology varies from dissipative to reflective. Dissipative beaches are rela- 
tively flat with subaqueous bars (resulting in a wide surf zone), whereas reflective beaches are characterized by steep beach slopes, coarse sand, narrow surf zones, and (at some shores) swash rips (Wright \& Short 1984). Dissipative and reflective beaches are 2 ends of a continuum of sandy beach morphodynamics (Wright \& Short 1984), but at rocky shores, surf zones are primarily reflective due to the steepness of the shore. Surf zone hydrodynamics differ considerably between dissipative and reflective shores. These diverse hydrodynamic conditions may lead to differential exchange of water, which may translate into differential larval settlement and recruitment. In a comparative study of recruitment of intertidal organisms to rocks on beaches along the coasts of Oregon and northern California, Shanks et al. (2010) found that much higher recruitment occurred at more dissipative than at reflective shores.

Several comprehensive field studies have been performed at dissipative beaches, such as Torrey Pines, CA (Seymour 1989), Duck, NC (Elgar et al. 2001), Monterey Bay, CA (MacMahan et al. 2005), and Truc Vert, France (Sénéchal et al. 2011). Recent studies have focused on understanding the cross-shore transport of material in the surf zone (Imperial Beach and Monterey Bay, CA). These recent efforts have shown that a primary mechanism for exchange at more dissipative beaches is related to rip currents that episodically pulse surf zone waters offshore (Reniers et al. 2009, MacMahan et al. 2010). Rip currents strengthen with increasing wave height and at low tides (MacMahan et al. 2005). However, despite these studies, the cross-shore exchange at dissipative beaches still requires further investigation. In contrast, the cross-shore exchange process at reflective beaches/shores has received much less attention. Theoretically, due to the lack of rip currents, reduction in undertow, and the narrow episodic surf zone, reflective beaches may afford a less efficient exchange of water between the surf zone and the region seaward of breaking waves than more dissipative shores.

Surface gravity waves evolve as they propagate from deep to shallow water, and in most cases the shoreward-propagating waves are dissipated near the shoreline by wave breaking (Thornton \& Guza 1983). There are, however, conditions when shoreward-propagating waves reflect at the shoreline (Elgar et al. 1994). Steep beaches are known for narrow, energetic surf (swash) zones and higher wave reflection which induces cross-shore standing wave patterns (Battjes 1974). In a laboratory setting, Miche (1951) empirically determined the amount of wave re- flection for normally incident monochromatic waves on a planar beach. Battjes (1974) also empirically related wave reflection, $R$, to the Iribarren number, $\xi$ :

$$
R=\sim 0.1 \xi^{2} \text { (when } \xi \leq 3 \text { ) }
$$

where:

$$
\xi=\frac{\tan \beta}{\sqrt{H_{\mathrm{b}} / L_{\mathrm{o}}}}
$$

where $\tan \beta$ is the beach slope from the breakpoint to the shore line, $H_{\mathrm{b}}$ is the wave height at breaking, and $L_{\mathrm{o}}$ is the deep water wave length, defined as:

$$
L_{\mathrm{o}}=\frac{g T^{2}}{2 \pi}
$$

where $g$ is gravitational acceleration and $T$ is the wave period. Eq. (2) relates beach slope to wave steepness $\left(H_{\mathrm{b}} / L_{\mathrm{o}}\right)$. Note that $R$ describes the ratio of seaward propagating wave height to shoreward propagating wave height; $R=1$ represents $100 \%$ reflection and $R=0$ represents zero wave reflection (i.e. $100 \%$ wave dissipation). $R$ estimates from natural beaches are limited (Elgar et al. 1994) and are often calculated from beaches that are mildly reflective ( $R \simeq 0.3$ for 0.05 to $0.15 \mathrm{~Hz}$ ) at higher tides with lower energy waves (Tatavarti et al. 1988, Elgar et al. 1994, Miles \& Russell 2004).

A field study to evaluate cross-shore exchange was performed over $40 \mathrm{~d}$ during the summer of 2011 at a steep beach at Carmel River State Beach, California. Here, we describe new physical and biological field observations obtained from that study. We first provide a description of the surf zone and nearshore waves, water temperature, and currents as an overview of this steep beach system. We then present evidence suggesting how detritus, along with competent larval invertebrates (i.e. those capable of settling and metamorphosing) may enter a reflective surf zone at a sandy beach. Significant correlations between the concentrations of detritus and a variety of competent larval invertebrates in the surf zone suggest that the mechanism of transport into reflective surf zones may be similar. These observations provide clues to the transport processes.

\section{MATERIALS AND METHODS}

In June and July 2011, a comprehensive biological and physical study was performed at Carmel River State Beach (CRSB) California (36 $32^{\prime} 18^{\prime \prime} \mathrm{N}, 121^{\circ}$ $\left.55^{\prime} 43^{\prime \prime} \mathrm{W}\right)$, a $0.6 \mathrm{~km}$ long pocket beach located at the 
mouth of the Carmel River (Fig. 1). The Carmel River periodically breached and closed on the south side of the beach during this experiment. The beach profile consisted of a 1:7.6 subaerial beach slope, 1:3 subaqueous beach step, and 1:19 subaqueous beach profile. There were no subaqueous bars or terraces; rocky intertidal zones were located at either end of the beach, and a large kelp bed was situated offshore at the northern end of the beach (Fig. 1). The bathymetry and upper beachface profiles were acquired by investigators walking with a global positioning system (GPS), and with a GPS- and echosounderequipped electric kayak.

A cross-shore array of 3 self-contained, continuously $1 \mathrm{~Hz}$ sampling, $2 \mathrm{MHz}$ Nortek Acoustic Doppler Current Profilers (ADCPs 1 to 3) was deployed be- tween 3 and $7 \mathrm{~m}$ tidally-averaged water depth and sampled ocean currents and waves for $40 \mathrm{~d}$ (instrument locations are presented in Fig. 1; positive is offshore and to the south). The ADCPs were mounted $\sim 35 \mathrm{~cm}$ above the seabed. Velocity measurements were obtained in $0.5 \mathrm{~m}$ bins; the bins near the wavy sea surface were removed, and the ADCPs did not measure velocities within $0.5 \mathrm{~m}$ of the bottom. The ADCPs also recorded the pressure and bottom water temperature at $1 \mathrm{~Hz}$. A fourth ADCP (ADCP 4; Fig. 1) was deployed in $12 \mathrm{~m}$ water depth and measured waves (e.g. wave height and period) for $40 \mathrm{~min}$ in a burst mode every hour. Additionally, an array of 6 Electromagnetic Current Meters (EMCMs) vertically spaced at $0.2 \mathrm{~m}$ was deployed for $5 \mathrm{~d}$ (Yeardays 169 to 173$)$ to observe the vertical structure of the cur-

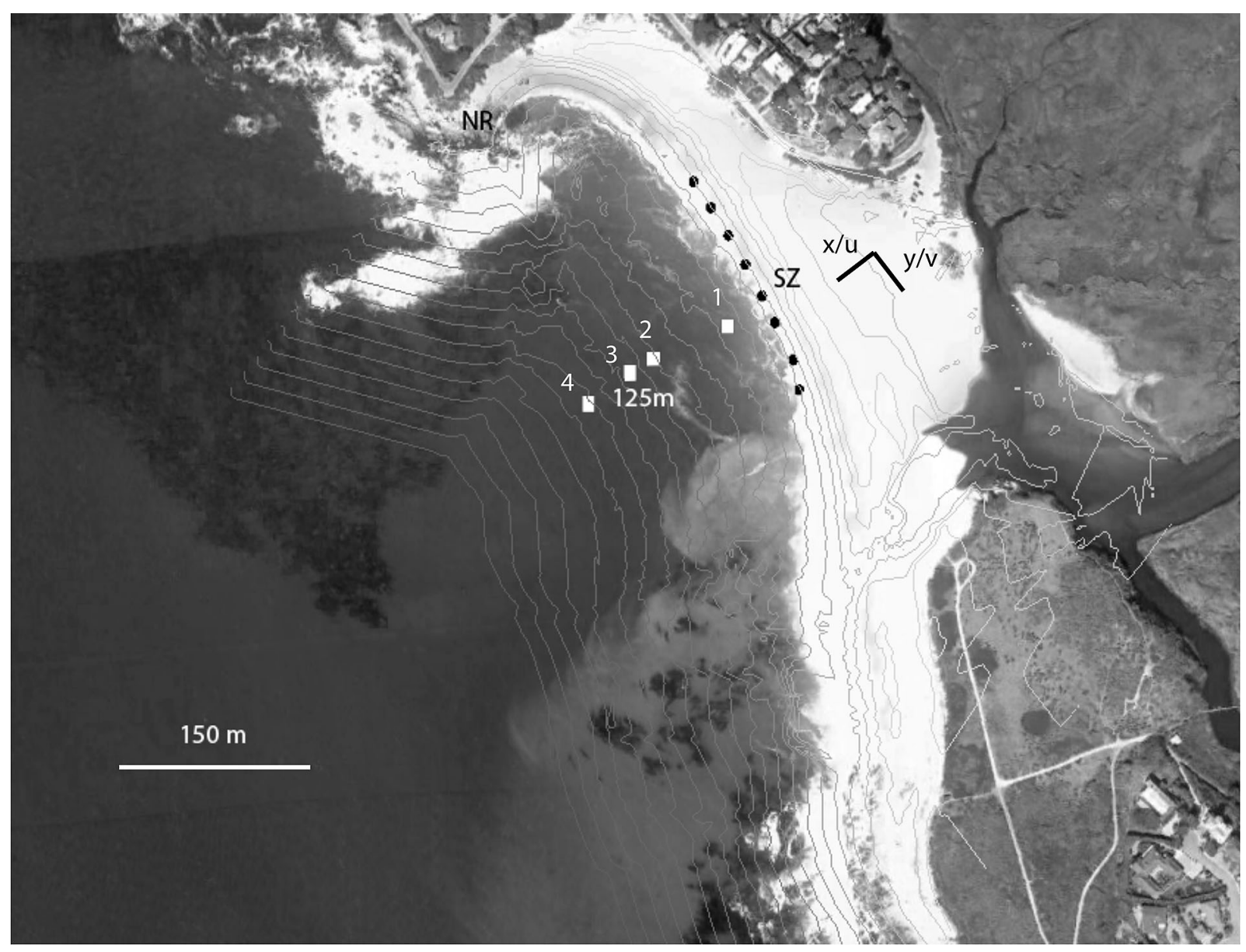

Fig. 1. Study site at Carmel River State Beach, California ( $\left.36^{\circ} 32^{\prime} 18^{\prime \prime} \mathrm{N}, 121^{\circ} 55^{\prime} 43^{\prime \prime} \mathrm{W}\right)$. Zooplankton samples were collected within the sandy beach surf zone (SZ) and $125 \mathrm{~m}$ seaward of the surf zone $(125 \mathrm{~m})$. White squares indicate the locations of the Acoustic Doppler Current Profiler (ADCP) moorings. ADCPs 1 to 3 measured currents; ADCP 4 measured waves. An Electromagnetic Current Meter (EMCM) was located at SZ, and the black circles indicate locations of fluorometers used during a concurrent dye study (J. A. Brown et al. unpubl. data). NR: north rocks where barnacle settlement was measured during a separate study (Shanks et al. 2014). The current data are reported relative to the orientation of the beach as indicated by the $x, y$ coordinate system. Modified from a Google Earth image 
rents associated with the steep beach surf/swash zone. The EMCM array was placed such that at low tide the current meters were often not submerged, while at high tide they were often fully submerged. The EMCMs were located inside and outside the region of active wave breaking as a function of tidal elevation and wave energy.

Zooplankton and detritus were collected from 15 June through 15 July, about $125 \mathrm{~m}$ offshore near ADCP 3 and inside the surf zone (labeled 125 and SZ, respectively; Fig. 1). Offshore samples were collected from a kayak in the morning hours before the increase in winds associated with the sea breeze (Hendrickson \& MacMahan 2009). Offshore samples were collected by vertical plankton tows using a $200 \mu \mathrm{m}$ mesh $0.25 \mathrm{~m}^{2}$ net that was equipped with a flow meter to determine the volume of water filtered. Three replicate samples were collected daily by hauling the net from near the bottom to the surface. The net filtered an average of $2 \mathrm{~m}^{3}$ per tow. In the surf zone, zooplankton samples were collected with a pump system. A $6 \mathrm{~cm}$ diameter hose was attached to pipes that were pushed deep into the sand with a jet of water; these pipes extended into the surf zone. A gas-powered pump sampled about $240 \mathrm{l}$ of water $\mathrm{min}^{-1}$, and $1.2 \mathrm{~m}^{3}$ of seawater was filtered for each of 3 replicate samples each day. Samples were collected within $1 \mathrm{~h}$ of high tide each day (the intake on the hose was out of the water at low tide) and were filtered through a $200 \mu \mathrm{m}$ mesh net. Depending on the wave height on a given day, these samples were collected within, or just a few meters seaward of the breakers. All samples were preserved in buffered formalin.

Zooplankton in the samples were enumerated using dissecting microscopes. Samples were processed following the techniques of Shanks \& Shearman (2009). Briefly, samples were washed free of formalin and then water was added until the sample reached a volume of about $200 \mathrm{ml}$. After agitating the sample, an aliquot was taken with a Stempel pipette. Aliquots were counted serially until about 200 of the common target organisms had been enumerated. Larvae were identified using Shanks (2001). All zooplankters in the aliquots were counted, but data for only a representative subset of taxa are reported here.

Detritus (small, on the order of mm diam. pieces of benthic algae and crustacean [primarily barnacle] molts) was abundant in the samples. Detritus sinks slowly through the water column, and hence may act as a relatively passive tracer of water movement. We enumerated detritus pieces in our samples using the techniques described above for counting zooplank- ton. We also measured detritus fall rates, using detritus from the surf zone pump samples. Single pieces or aggregates of detritus were carefully pipetted into a transparent tank $(11 \times 16 \times 30 \mathrm{~cm})$ filled with surf zone seawater. The detritus pieces were allowed to sink through $15 \mathrm{~cm}$, and their sinking rate over the next $5 \mathrm{~cm}$ was measured.

If water in the surf zone is freely exchanged with water offshore, then concentrations of organisms and detritus in the surf zone should correlate with concentrations offshore. To test this, we ran correlations between concentrations of each taxon and detritus inside and outside the surf zone. The abundance of some organisms within the surf zone appeared to vary with the abundance of detritus. This apparent relationship was investigated by running correlations between the concentrations of detritus and representative taxa of holoplankters, precompetent and competent larvae. The exchange of surf zone water with offshore water at dissipative beaches with rip currents is known to vary with wave height (Reniers et al. 2009). To investigate the effect of wave height on surf zone concentrations of organisms and detritus, the daily average hourly root-mean-squared wave height was correlated to the surf zone concentrations of detritus, competent larval invertebrates and organisms often associated with detritus.

\section{Wave reflection}

Owing to the steep beach profile, shoreward (+) and seaward (-) energy, $E$, from the co-located pressure and ADCP velocities (2nd bin from the bottom) was computed as:

$$
E^{ \pm}(f, x)=\frac{1}{4}\left[\begin{array}{l}
\frac{C o_{p p}(f, x)}{\left(\frac{\cosh \left[k\left(h+z_{p}\right)\right]}{\cosh (k h)}\right)^{2}}+\frac{C o_{u u}(f, x)}{\left(\frac{g k \cosh \left[k\left(h+z_{u}\right)\right]}{\omega \cosh (k h)}\right)^{2}} \\
\pm 2\left(\frac{C o_{p u}(f, x)}{\left(\sqrt{\left.\left(\frac{\omega}{g k}\right)^{2} \frac{\cosh \left[k\left(h+z_{p}\right]\right.}{\cosh \left[k\left(h+z_{u}\right]\right.}\right)}\right)}\right]
\end{array}\right]
$$

where Co represents the co-spectrum, $f$ is frequency, $x$ is cross-shore location, $k$ is radian wave number, $z$ is instrument height, $h$ is water depth, $\omega$ is radian wave frequency, and subscripts $u$ and $p$ represent cross-shore velocity and pressure (Tatavarti et al. 1988, Sheremet et al. 2002). The energy flux, F, is defined as:

$$
F^{ \pm}(f)=E^{ \pm} C_{g}
$$



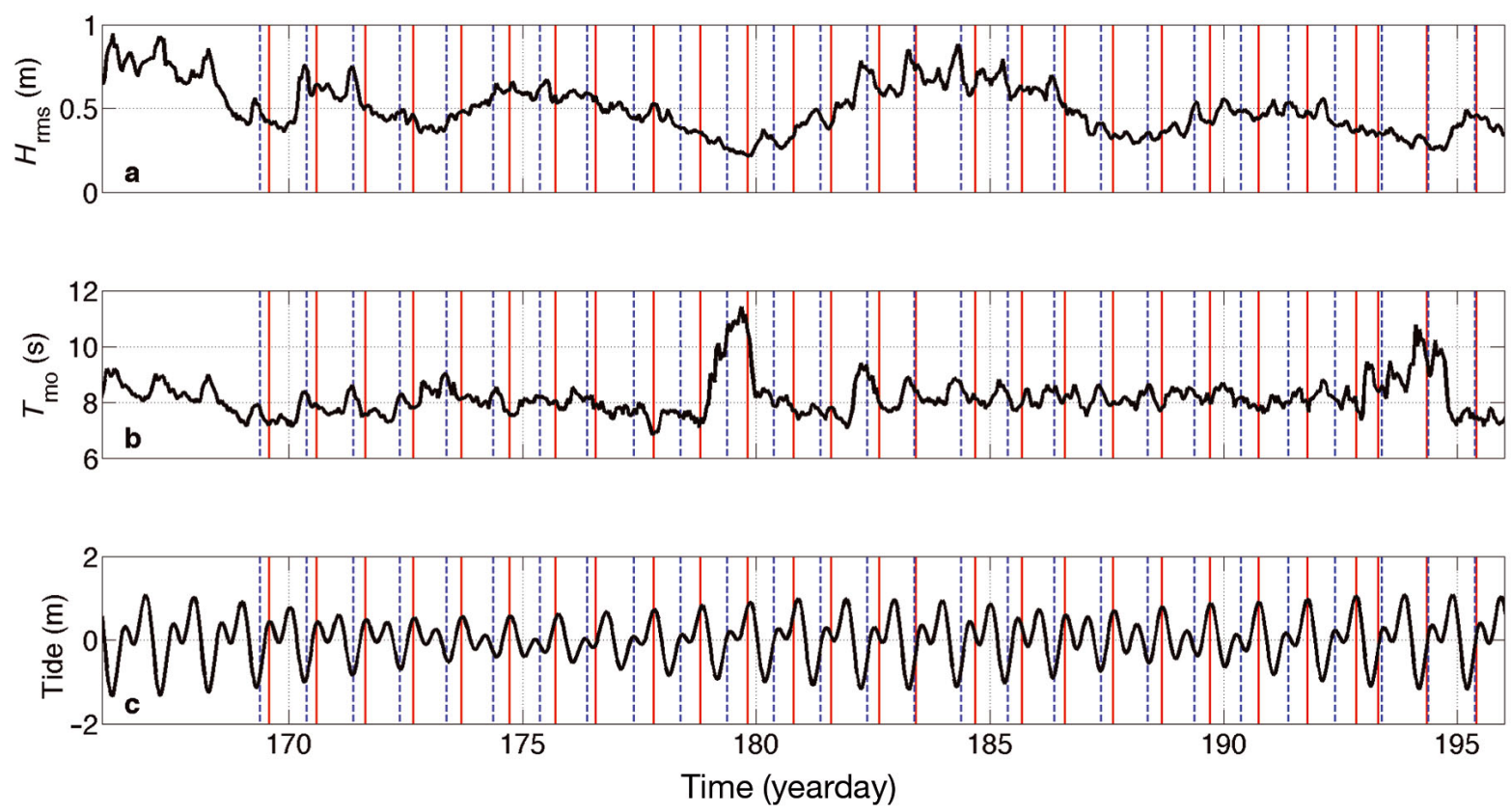

Fig. 2. (a) Wave height, (b) wave period, and (c) tidal elevation measured at Acoustic Doppler Current Profiler (ADCP) 3. Vertical lines: times of biological samples; red lines: surf zone sampling; blue dashed lines: offshore sampling. Note that the long-period modulations of wave height represent synoptic storm variability

where $C_{g}$ is the wave group velocity. Reflection is calculated as:

$$
R^{2}(f)=F^{-}(f) / F^{+}(f)
$$

and the reflection coefficient for the sea-swell is:

$$
R_{\mathrm{SS}}^{2}=\int_{0.05 \mathrm{~Hz}}^{0.15 \mathrm{~Hz}} R^{2}(f) d f
$$

Note that the sea-swell (ss) subscript has been dropped for convenience. The incoming root-meansquared wave height, $H_{\mathrm{rms}}$ and mean wave period, $T_{\text {mor }}$ are computed from the onshore energy $\left(E^{+}\right)$ spectral estimates (Fig. 2a,b). This method (Eqs. 5 \& 6) biases instrument noise as reflection. The cospectrum, however, does not include any instrument noise. Therefore, the spectral noise floor is removed from $\mathrm{Co}_{p p}$ and $\mathrm{Co}_{u u}$ to remove potential noise bias.

\section{Stokes drift}

The Eulerian frame of reference does not describe the path of particles (i.e. biological transport). In the Lagrangian (or particle-following) reference frame, the time-averaged, second-order velocity of a water parcel in a wave results in a depth-varying net drift in the direction of wave propagation (Stokes 1847), referred to as Stokes velocity, $u_{\text {Stokes }}$. In the Eulerian reference frame (which is fixed in space), waverelated volumetric transport occurs between the wave trough and crest. In the inner shelf in the Lagrangian reference frame, $u_{\text {Stokes }}$ is largest near the water surface and decays exponentially with depth, given by:

$$
u_{\text {Stokes }}(z)=\frac{\omega k H_{\mathrm{mo}}^{2} \cosh [2 k(h+z)]}{16 \sinh ^{2}(k h)}
$$

The theoretical depth-integrated $u_{\text {Stokes, }} Q_{\text {Stokes, }}$ is the same in both the Lagrangian and Eulerian reference frames, and is given by:

$$
Q_{\text {Stokes }}=\frac{g H_{\mathrm{mo}}^{2}}{16 c}
$$

where $H_{\text {mo }}$ is significant wave height, and $c$ is wave phase speed (Stokes 1847). In a wave environment with the presence of a background flow, the waveaveraged Lagrangian velocity, $u_{\mathrm{L}}(Z)$, can be estimated as:

$$
u_{\mathrm{L}}(Z)=u_{\mathrm{E}}(Z)+u_{\text {Stokes }}(Z)
$$

where $u_{\mathrm{E}}(Z)$ is the Eulerian flow velocity of the background flow, the vertical elevation $(Z)$ is positive upward relative to mean sea level (MSL), and posi- 
tive $u$ is offshore. The Lagrangian volumetric transport or depth-integrated $u_{\mathrm{L}}, Q_{\mathrm{L}}$, is defined as:

$$
Q_{\mathrm{L}}=Q_{\mathrm{E}}+Q_{\text {Stokes }}
$$

where $Q_{\mathrm{E}}$ is the depth-integrated $u_{\mathrm{E}}$. The depthaveraged velocity, $\overline{u_{\text {Stokes }}}$ or $\overline{u_{\mathrm{E}}}$, can be estimated by dividing $Q_{\text {Stokes }}$ or $Q_{\mathrm{E}}$ by the local $h$. To illustrate the expected vertical and cross-shore distribution of both $u_{\mathrm{E}}(Z)$ and $u_{\mathrm{L}}(Z)$ velocities at CRSB, a profile model of the wave transformation and concomitant Eulerian flows was used (Reniers et al. 2004) to which the Stokes drift (Eq. 8), was added. The model describes the wave-induced Eulerian flow below the wave trough level, including streaming within the near-bed wave boundary layer (Longuet-Higgins 1953). Streaming results from the dissipation of wave energy close to the bed due to bottom friction generating a small but steady flow in the direction of wave propagation.

\section{RESULTS}

\section{Wave reflection}

Consistent with theory, small waves with longer periods were reflected more than larger waves with
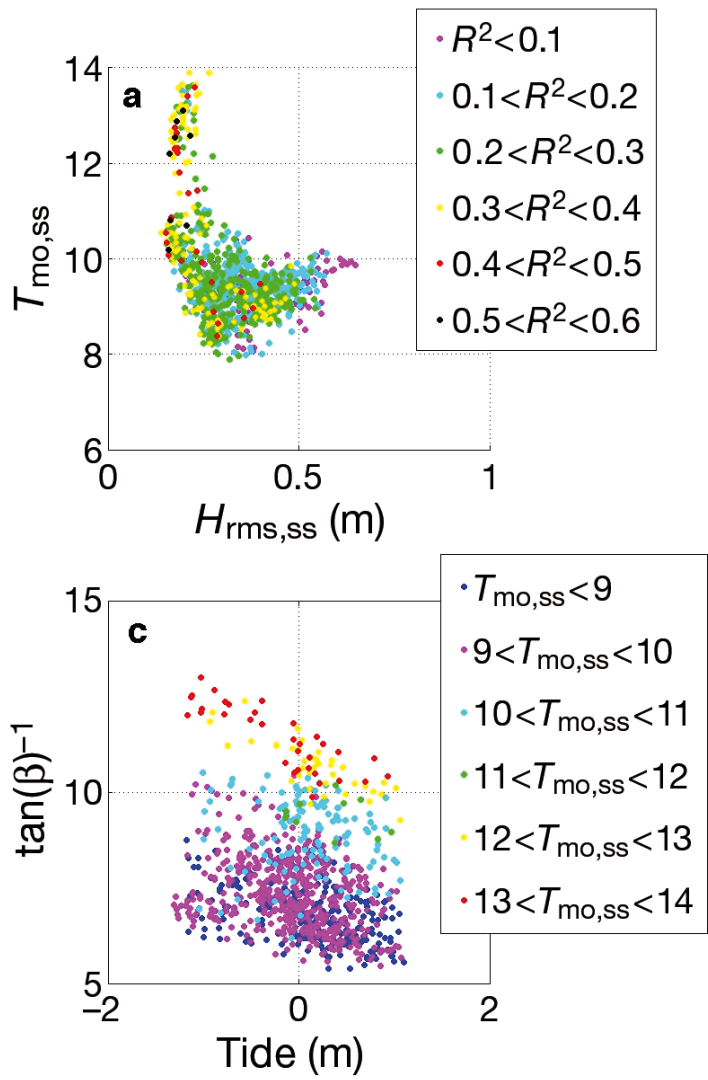

short periods, highlighted by the color transition of $R^{2}$ seen in Fig. 3a. Elgar et al. (1994) showed that $R^{2}$ is dependent on tidal elevation, owing to the fact that waves reflect with different beach slopes, and beach slope often changes with tide level. Even though the upper beach slope was relatively constant over the tidal range of -1 to $+1 \mathrm{~m}$, excluding waves with $T_{\mathrm{mo}}>$ $10.5 \mathrm{~s}$ (where $T_{\mathrm{mo}}$ is the wave period calculated from the first order spectral moment; Fig. $3 \mathrm{~b}$ ), $R^{2}$ was surprisingly influenced by tidal level. Though a tidal relationship is found with $R^{2}$ estimates, it is believed to be a function of the wave refraction and shoaling associated with the offshore submarine canyon, not a function of the beach slope.

One of the difficulties in predicting wave reflection on a natural beach is determining the appropriate beach slope, so instead we computed the beach slope from field observations (Fig. 3c) by solving for $\tan \beta$ in Eq. (2):

$$
\tan \beta=\sqrt{\frac{R H_{\mathrm{rms}}}{0.1 L_{\mathrm{o}}}}
$$

where $L_{\mathrm{o}}$ is based on $T_{\mathrm{mo}}$. As Elgar et al. (1994) mentioned, the empirical $R$ relationships are based on monochromatic waves on planar, non-porous beaches, not random waves on complex beach pro-

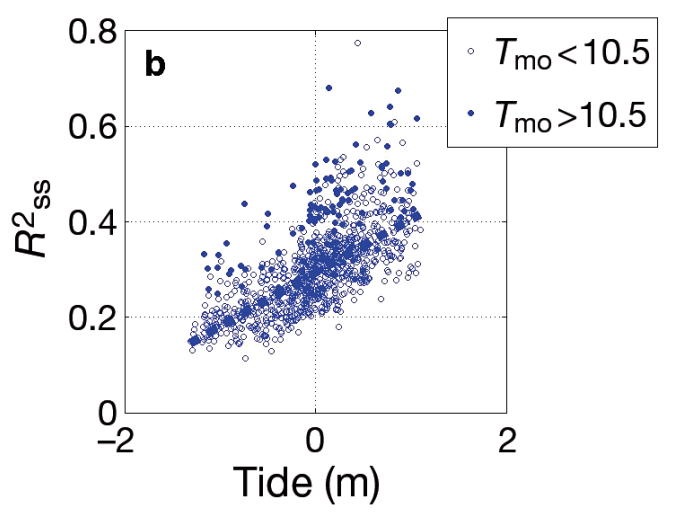

Fig. 3. Bulk statistics of wave reflection $\left(R^{2}\right.$; colored dots) described as function of (a) mean wave period, $T_{\text {mo, }}$ and rootmean-squared wave height, $H_{\text {rms }}$ and (b) tidal elevation. (c) The inverse of the beach slope plotted against tidal height. ss: sea-swell wave period in seconds 


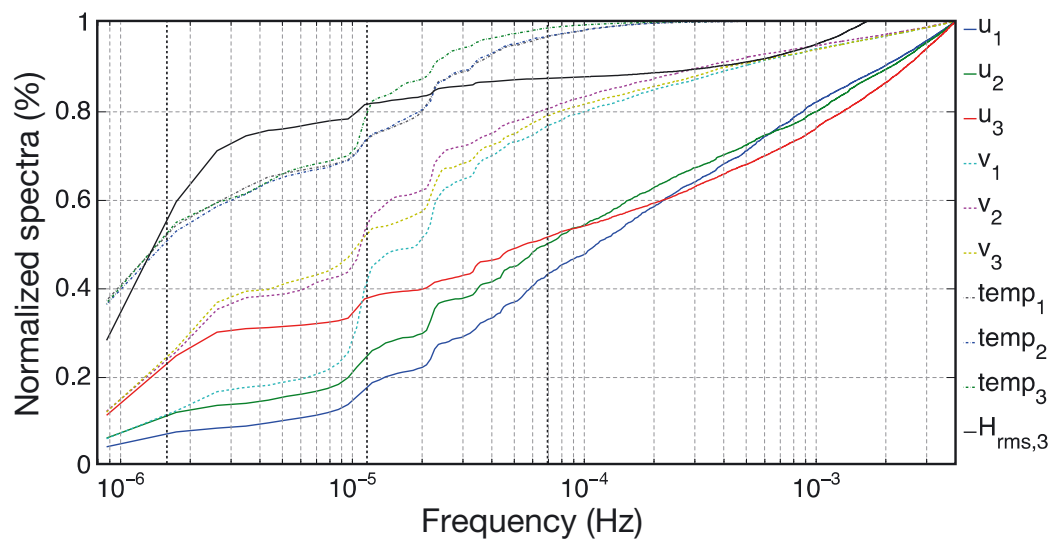

Fig. 4. Normalized cumulative spectra for cross-shore velocity $(u)$, alongshore velocity $(v)$, water temperature (temp), and 5 min estimated root-meansquared wave height $\left(H_{\text {rms }}\right)$ for Acoustic Doppler Current Profilers (ADCPs) 1 to 3. Vertical dashed lines from left to right represent the frequency delineation for storms, tides, and very low frequency surf zone motions (VLFs)

\section{Depth-averaged currents and water temperature signals}

Spectral estimates of cross-shore velocity, alongshore velocity, and water temperature at ADCPs 1 to 3 were computed using a 13.3 d Hamming window with a $50 \%$ overlap for the $40 \mathrm{~d}$ time signal, resulting in 16 degrees of freedom. The spectral estimates were cumulatively integrated over all frequencies up to $0.004 \mathrm{~Hz}$ and normalized by this variance, such that spectra describe the percentage of variance. Normalized cumulative spectra allow data of different scales and percentage of variance to be evaluated simultaneously in one figure. A number of temporal bands were defined: synoptic storm ( $>7 \mathrm{~d})$, subtidal $(>25 \mathrm{~h})$, tidal (4 to $25 \mathrm{~h}$ ), very low frequency surf zone motions (VLF; $4 \mathrm{~min}$ to $4 \mathrm{~h}$ ), infragravity (IG; $25 \mathrm{~s}$ to $4 \mathrm{~min}$ ), and seaswell waves ( $\mathrm{ss} ; 5$ to $25 \mathrm{~s}$ ). The relative importance of the slower ( $>4 \mathrm{~min}$ ) motions is presented in Fig. 4. During the study period, synoptic storm events were associated with increased currents and decreased water temperature. The synoptic storm temporal band describes approximately $5 \%$ of the variability in cross-shore and $20 \%$ of the alongshore velocity variance of the slower motions. Storms were responsible for approximately $50 \%$ of the wave activity and temperature variability. The subtidal temporal band, which also includes shorter duration storms, describes $15 \%$ of the variability in cross-shore velocity, alongshore velocity, and temperature. Approximately $25 \%$ of the variability in wave height was associated with the subtidal temporal band. Hence, wave height and temperature variability were primarily due to synoptic and tidal motions. The semi-diurnal and diurnal tides were responsible for another $20 \%$ of the cross-shore velocity, alongshore velocity, and temperature variability. Thus, approximately $50 \%$ of the cross-shore velocity variability was associated with VLF motions, whereas only $20 \%$ of the alongshore velocity variability was associated with VLF motions. The standard deviations for the slower cross- and alongshore (>4 min) velocities were 0.02 and $0.04 \mathrm{~m} \mathrm{~s}^{-1}$, which represents 7 and $33 \%$ of the total energy including IG and incident motions. Hence, most of the variability in cross-shore and alongshore motions are described by the sea-swell waves. Even though the slow velocity motions (>4 min) were relatively small, their importance for associated with more dissipative beaches. 

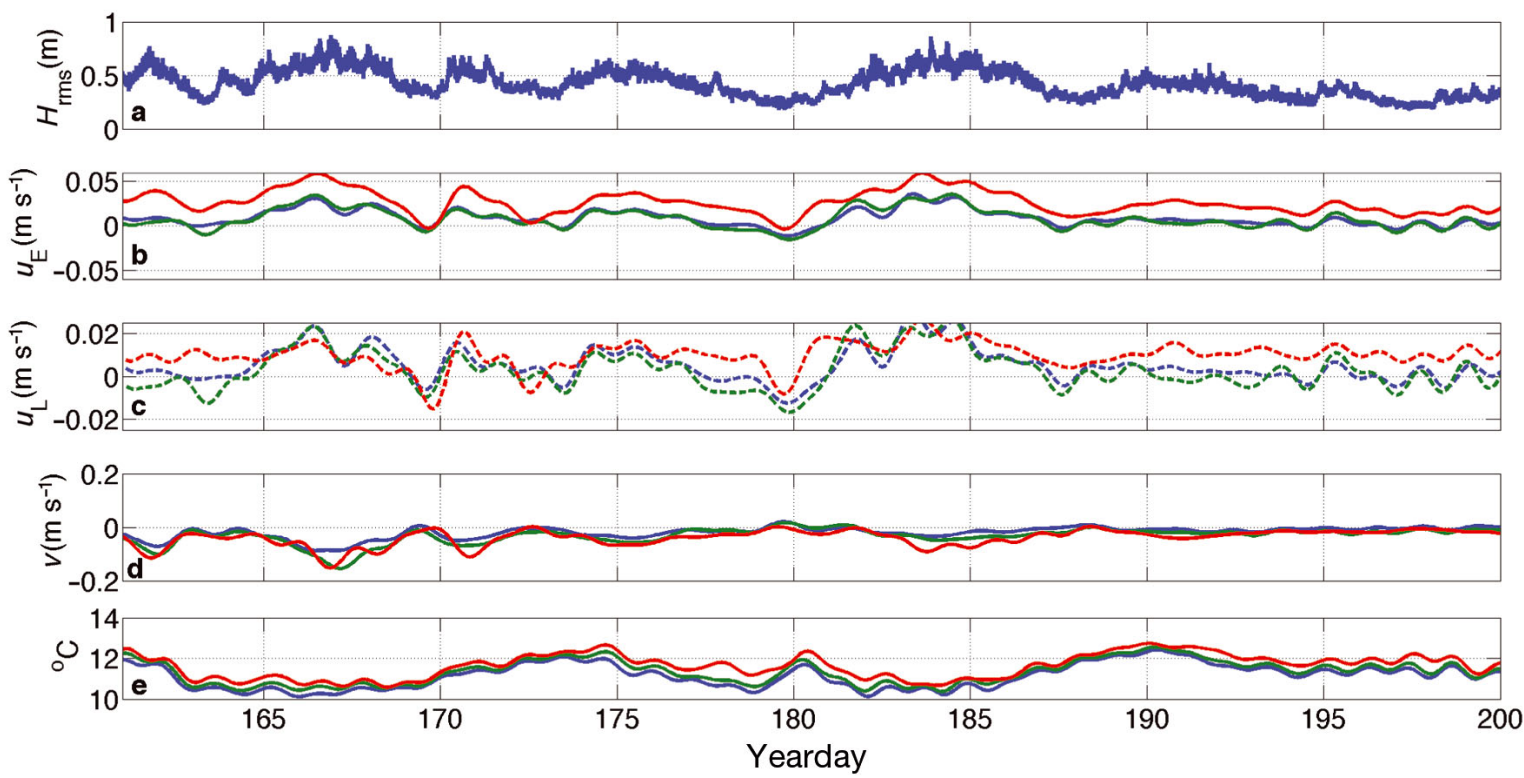

Fig. 5. (a) Root-mean-squared wave height $\left(H_{\mathrm{rms}}\right),(\mathrm{b}, \mathrm{c})$ synoptic subtidal low-pass filtered cross-shore (b) Eulerian velocity $\left(u_{\mathrm{E}}\right)$ and (c) Lagrangian velocity $\left(u_{\mathrm{L}}\right),(\mathrm{d})$ alongshore Eulerian velocity $(v)$, and (e) water temperature at Acoustic Doppler Current Profilers (ADCPs) 1 to 3 (red, green, blue). Positive is seaward and to the north

transporting material is significant owing to their long durations.

The hourly mean cross- and alongshore velocities from the ADCPs were depth-averaged and low-pass filtered in order to describe the subtidal and synoptic variation. The cross- and alongshore velocities increased with decreasing water depth (Fig. 5b,d). The velocities are correlated with incoming wave energy, suggesting that they were wave-induced (Fig. 5a, b,d). Outside the surf zone, in the inner shelf with zero wind stress, Hasselmann (1970), Xu \& Bowen (1994), Monismith et al. (2007), Smith (2006) and Lentz et al. (2008) established the presence of a wave-driven, seaward-directed return flow. This wave-driven seaward-directed flow measured at CRSB was generally largest near the surface (data not shown), consistent with theory and field observations (Lentz et al. 2008). This suggests that partial dissipation of the incident waves on this reflective beach supports the development of an inner-shelf return flow. In contrast, when the wave height was low (e.g. yearday 180), the cross-shore velocity was directed onshore (Fig. 5a,b).

Accounting for depth-averaged Stokes velocity in the observed depth-averaged Eulerian ADCP measurements reduces the offshore transport during synoptic storms, and enhances the onshore transport during small waves (Fig. 5c). When the waves are large, the non-zero Lagrangian transport is associated with additional flow patterns on this beach (dis- cussed below). The Lagrangian Stokes in the alongshore is minimal due to wave refraction, which orients the wave crest close to parallel with the shoreline near wave breaking. The depth-averaged Eulerian alongshore velocities within the surf zone represent transport, and were predominantly to the south throughout the experiment.

Outside of the surf zone at ADCP 1, a return flow profile was also observed, which had maximum offshore flow below the wave trough and decreased with depth (Fig. 6), consistent with return flow profiles measured on the inner shelf by Lentz et al. (2008). When the EMCM was within the surf zone, the return flow consisted of an undertow with maximum offshore velocities in the lower part of the water column (Fig. 6). When the EMCM array was outside of the surf zone, the magnitude of the return flow was similar to that measured by the ADCP at corresponding times. The magnitude of the alongshore velocity at ADCP 1 was less than that measured by the EMCM array for corresponding times (J. A. Brown et al. unpubl. data). These results indicate that outside of the surf zone, there is a decrease in velocity with increasing water depth.

\section{Biological results}

Concentrations of representative holoplankters (e.g. calanoid copepods, copepod nauplii, and euphausiid 


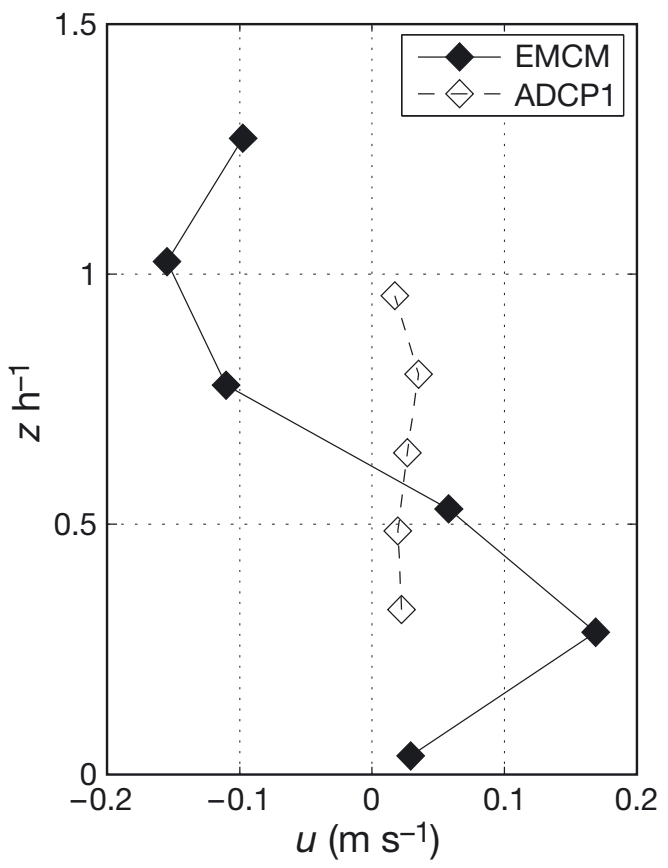

Fig. 6. Mean cross-shore velocity $(u)$ measured at low tide (Yearday 170.23) by the Electromagnetic Current Meter (EMCM) array at the edge of the surf zone (solid symbols) and by Acoustic Doppler Current Profiler (ADCP) 1 outside the surf zone (open symbols) as a function of depth-normalized height above the seabed (redrawn from J. A. Brown et al. unpubl. data)

larvae) and precompetent meroplankters (e.g. barnacle nauplii I to III and IV to VI) in the surf zone were not significantly correlated with their concentrations offshore, and surf zone concentrations were much lower than concentrations offshore (Fig. 7). Surf zone concentrations of a competent meroplankter (cyprids) were also not correlated with offshore concentrations; however, concentrations in the surf zone were often higher than offshore (Fig. 7). These data suggest that hydrodynamics, coupled with zooplankton behavior, may limit ingress into the surf zone for some taxa (i.e. holoplankters and precompetent meroplankters), whereas competent meroplankters are able to enter the surf zone at times and become concentrated there relative to their concentrations in nearshore waters.

Our analysis of the zooplankton samples revealed an apparent relationship between the concentrations of detritus and a variety of meroplankters in the surf zone. The sandy beach surf zone is not a source of detritus as there is no habitat for benthic algae or adult barnacles (the dominant sources of detritus); however, the offshore habitat and adjacent rocky intertidal habitats are sources of detritus. The surf zone is also not a source of competent larvae, all of which must enter the surf zone from the waters seaward of the surf zone. The concentration of detritus at the offshore station was not correlated with that in the surf zone (Fig. 7) and, similar to competent larval invertebrates, the concentration of detritus was higher in the surf zone than offshore on about half the dates. Like competent larvae, detritus has the capacity to enter the surf zone and accumulate there such that surf zone concentrations were higher than offshore on many dates.

Detritus particles are obviously without behavior, but they do not perfectly follow the movement of water: they sink. Detritus fall velocity averaged $2.4 \mathrm{~mm} \mathrm{~s}^{-1}$ (Fig. 8); therefore, the average detritus particle could, under conditions of low turbulence and a $2 \mathrm{~m}$ deep water column (the depth just outside the surf zone), sink from the surface to the bottom in minutes.

The surf zone concentrations of detritus were not correlated with the concentrations of representative holoplankters (copepods, copepod nauplii, and euphausiid larvae) and precompetent meroplankters (bivalve larvae and barnacle nauplii; Fig. 9). Surf zone detritus concentrations were, however, positively correlated with concentrations of competent larval invertebrates (e.g. gastropods, polychaetes, cyprids, bopyrid amphipods) and organisms that could have been associated with detritus (e.g. harpacticoid copepods and amphipods) (Fig. 10). From 34 to $69 \%$ of the daily variation in the abundance of these taxa in the surf zone was explained by the daily variation in the concentration of detritus in the surf zone (Fig. 10).

Average wave height during the hour that zooplankton samples were collected in the surf zone was, in most cases, significantly negatively correlated with the concentrations of detritus and competent larval invertebrates, and organisms associated with detritus (Fig. 11). However, this relationship was marginally non-significant $(p=0.07$ ) for gastropod larvae, and the concentration of amphipods in the surf zone was not related to wave height. During periods of smaller waves, the concentration of detritus and a variety of invertebrate taxa were higher in the surf zone.

\section{DISCUSSION}

There are 2 main observations from this work. (1) Concentrations of holoplankton and precompetent larvae in the surf zone were not correlated with their concentrations just offshore, and on many days 


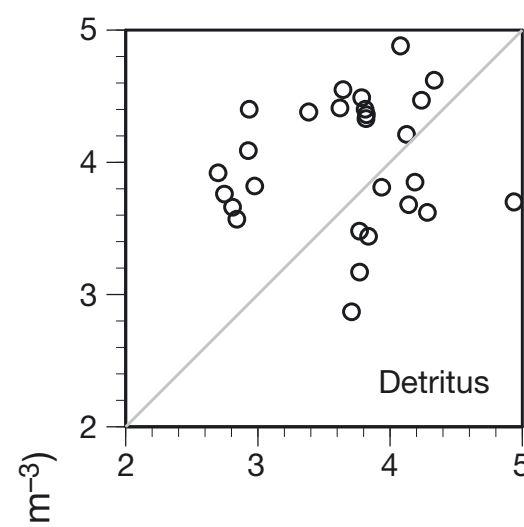

Fig. 7. Relationship between the log concentration of detritus and representative zooplankton at a station located $125 \mathrm{~m}$ offshore in the surf zone at Carmel River State Beach, California. Top panel: detritus; middle panels: calanoid copepods, copepod nauplii, and euphausid larvae; bottom panels: stage I to III barnacle nauplii, stage IV to VI barnacle nauplii, and cyprids. Only cyprids settled in the intertidal zone. Diagonal line indicates a 1-to-1 relationship between concentrations of zooplankton inside and outside the surf zone. Correlations between the variables were not significant
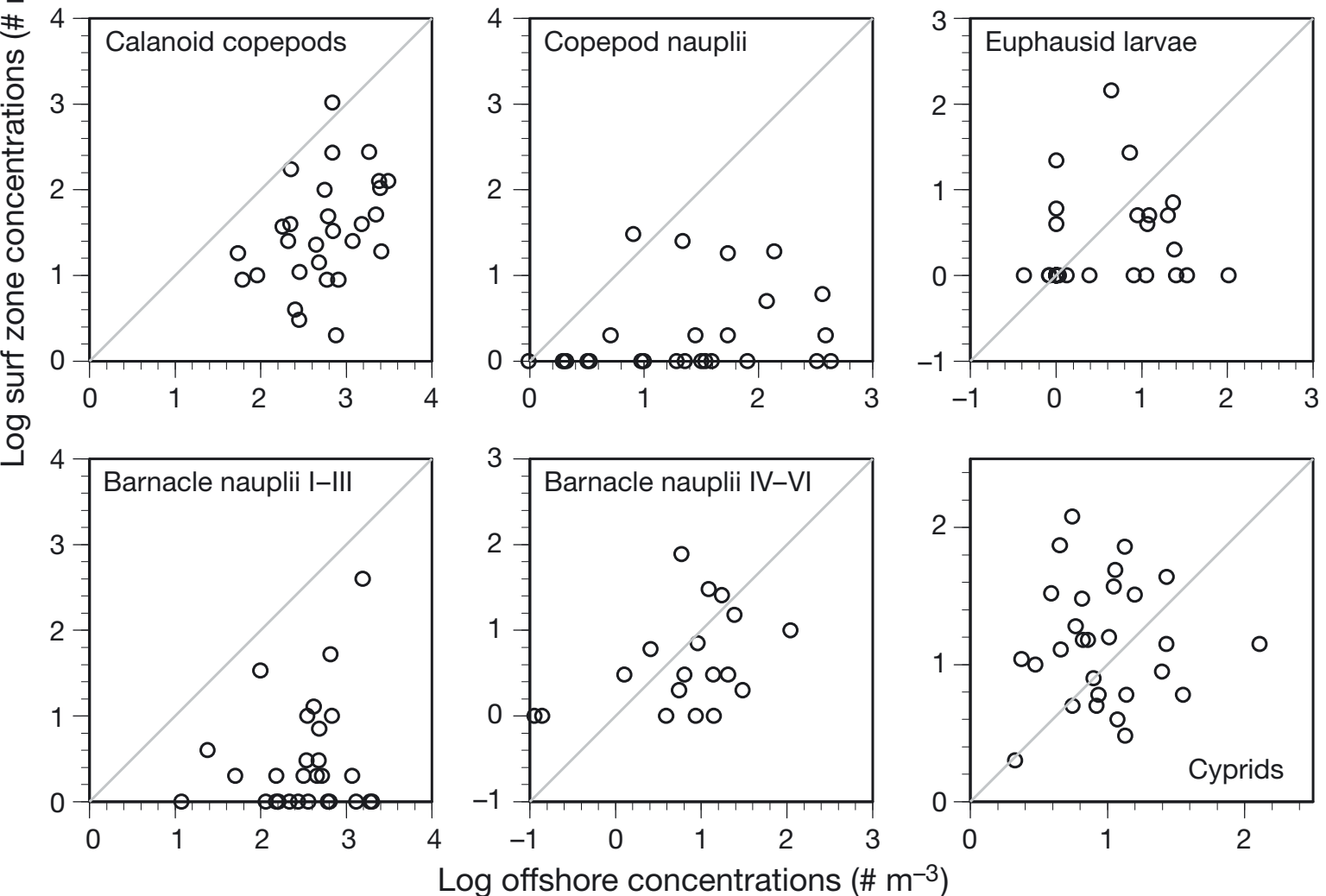

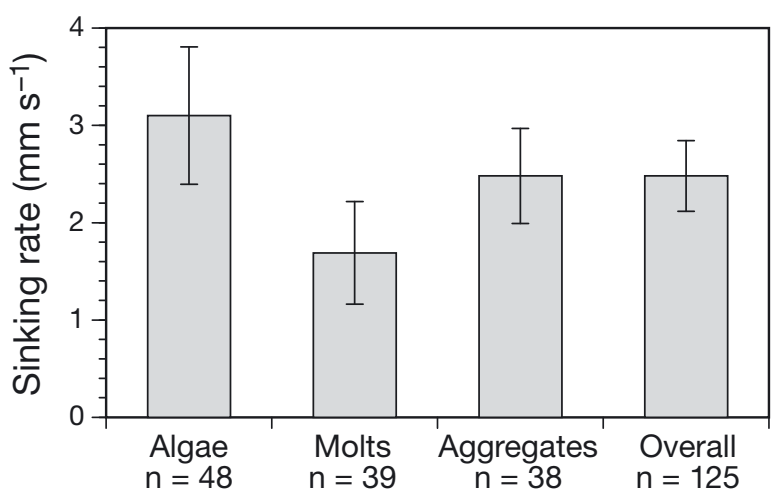

Fig. 8. Average $( \pm 95 \% \mathrm{CI})$ sinking rate of detritus: algae ( $\sim \mathrm{mm}$ diam.), crustacean molts, aggregates of algae and molts, and all data combined, where $\mathrm{n}$ is the number of independent observations were 1 to 2 orders of magnitude lower than their concentrations offshore. There was a similar relationship between the concentrations of phytoplankton in and out of the surf zone (Shanks et al. 2014); these organisms somehow avoided or were prevented from entering the surf zone. (2) Detritus, organisms often associated with detritus, and competent larvae were also not correlated with offshore concentrations, but on many days their concentrations in the surf zone were 1 to 2 orders of magnitude higher than offshore. In addition, concentrations of detritus, detritus-associated organisms, and larvae were correlated, suggesting that the same conditions caused detritus and competent larvae to accumulate in the surf zone. 

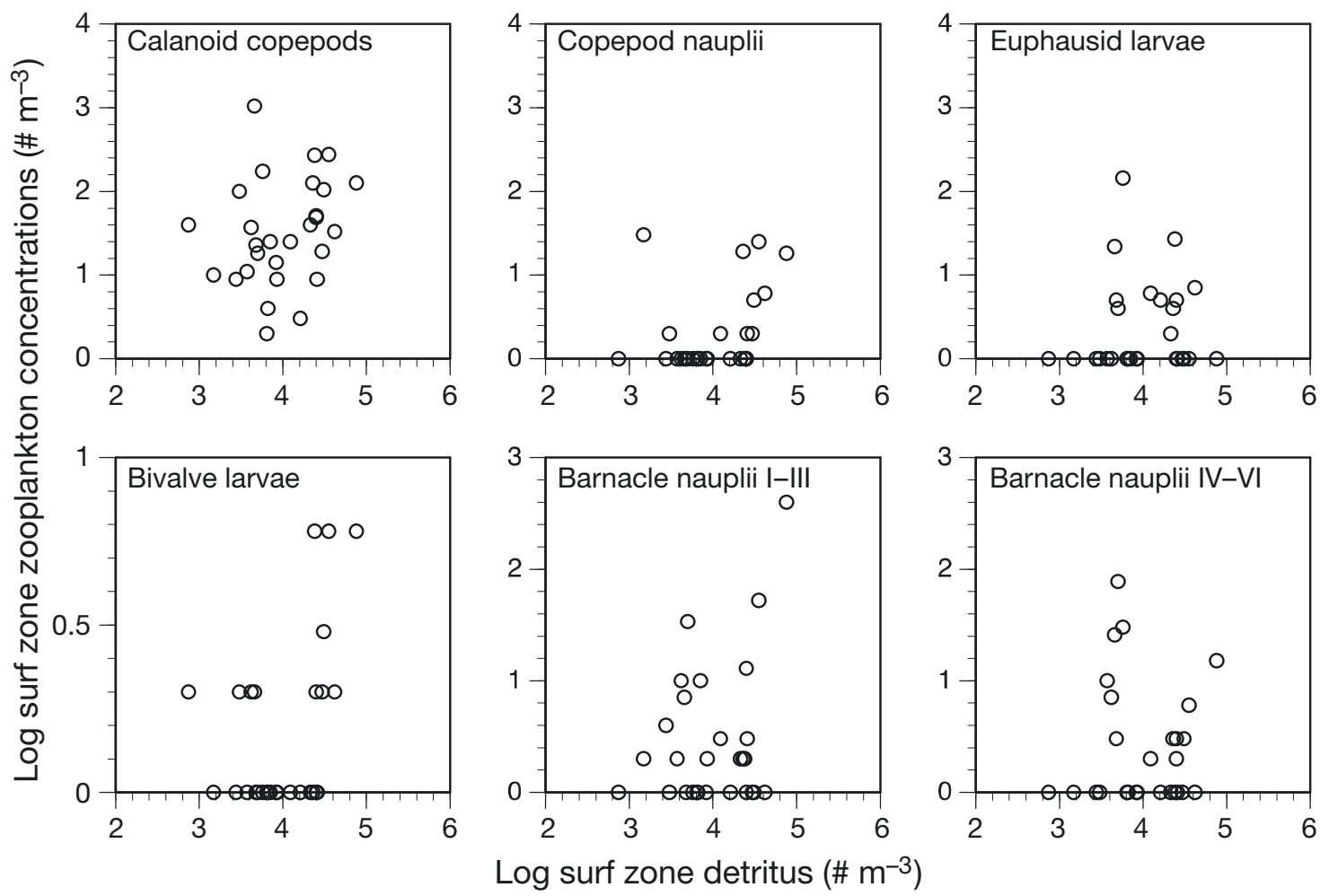

Fig. 9. Relationship between the log concentration of detritus and representative holoplankton (top row) and precompetent meroplankton (middle row) in the surf zone at Carmel River State Beach, California. Correlations between the variables were not significant

How might holoplankters, precompetent larvae, and phytoplankton avoid entering the surf zone? Since the enumerated phytoplankton (diatoms; Shanks et al. 2014) do not swim and most precompetent larvae and many holoplankters swim slowly, avoidance of the surf zone cannot be due to these organisms swimming away; rather, surf zone hydrodynamics must keep them out of the surf zone. The cross-shore flow measured at the outer edge of the surf zone by the EMCM array was shoreward near the surface and seaward throughout the water column (Fig. 5, J. A. Brown et al. unpubl. data). Fig. 12a shows modeled Eulerian current data below the wave trough (corresponding to the lower part with offshore flows in Fig. 6, with $z / h<0.6$ ) from shore out to $150 \mathrm{~m}$ using a profile model with normally incident waves of $0.6 \mathrm{~m}$ root-mean-squared wave height and a period of $8 \mathrm{~s}$. The model results clearly show the offshore flow, the undertow within the bulk of the water column at the outer edge of the surf zone generated by the breaking waves and, including the Stokes drift, an onshore surface flow at the surf zone edge (Fig. 12b). Given these observed currents, organisms close to the sea surface may be transported into the surf zone. In contrast, at the outer edge of the surf zone the undertow should push organisms within the water column away from the surf zone. We hypothesize that holoplankton, precompetent meroplankton, and phytoplankton tend to be located deeper in the water column. If they are at low concentrations within the surface layer then only a small percentage of the community will be carried into the surf zone; the concentration of organisms in the surf zone should be similar to their concentration in the near-surface waters just beyond the breakers, which is transported by breaking waves into the surf zone. A variety of meroplankters swim down in strong turbulence (Fuchs et al. 2004), a condition that they would encounter at the outer edge of the surf zone. Such behavior, if common amongst zooplankton, would tend to move plankters out of the water flowing onshore, and into that moving offshore.

We found strong positive correlations between the concentration of detritus in the surf zone and the concentrations of organisms that might be associated with detritus (e.g. amphipods and isopods) and competent larval invertebrates. We also found strong negative correlations between average daily wave height and the concentration of detritus, detritusassociated organisms, and competent larval invertebrates: concentrations were highest when waves were small. We propose 2 hypotheses that might 


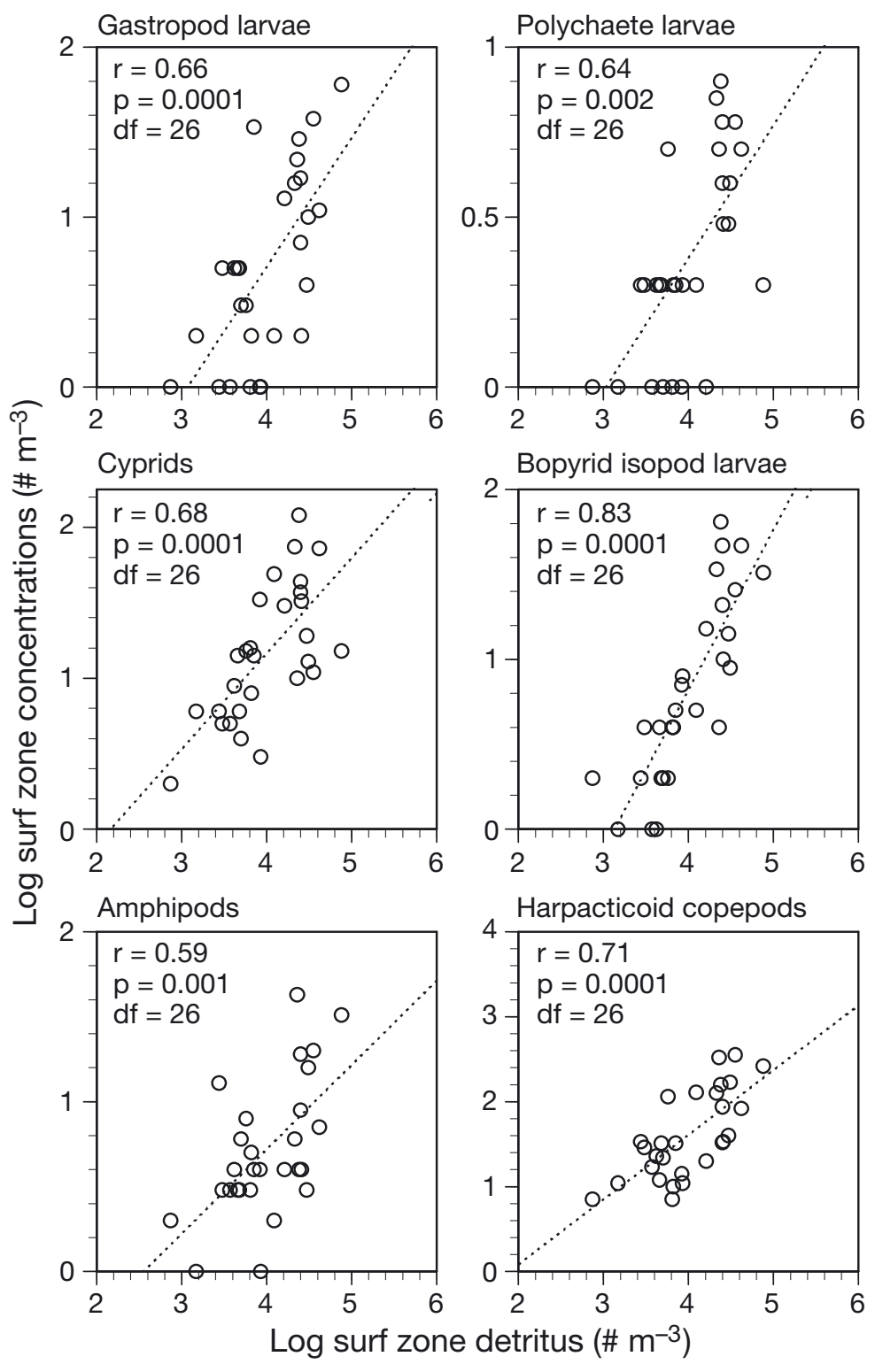

Fig. 10. Log concentration of detritus (algae and crustacean molts) in the surf zone relative to 4 competent meroplankters (gastropod, polychaete, cyprids, and bopyrid isopods) and 2 organisms that may be associated with detritus (amphipods and harpacticoid copepods). The dotted line and statistics are from correlation analyses

and associated zooplankton might have entered the surf zone with this flow, 3 lines of evidence suggest that this is likely not the primary source of this material within the surf zone. (1) If the water feeding into the alongshore current was the source of detritus and zooplankton, then concentrations of detritus should have been correlated with holoplankters and precompetent meroplankters, since all of these organisms would have been transported into the alongshore current by this onshore flow. Instead, only organisms that might be physically associated with detritus and competent meroplankters were correlated with detritus in the surf zone. (2) Over the course of the study, we measured the daily settlement of barnacle cyprids onto rocks at the northern end of the beach (labeled NR in Fig. 1) (Shanks et al. 2014). These rocks occur where the hydrographic model (Fujimura et al. 2013) suggests that the onshore flow hits the shore and turns to become the alongshore current. If this current transported offshore plankton to the shore, cyprid settlement should be highbut only 1 cyprid settled during $38 \mathrm{~d}$ of sampling. Therefore, the onshore flow was not a source of cyprids. (3) The onshore current should also have transported offshore phytoplankton into the surf zone. As part of this study, we sampled phytoplankton in the surf zone and offshore, including at the northern end of the beach (NR in Fig. 1, Shanks et al. 2014). The concentration of offshore phytoplankton taxa collected at the north rocks was only a small percentage (around 1\%) of that offshore (A. L. Shanks et al. unpubl. data). Therefore onshore flow, the source of the alongshore current, was not a source of offshore plankton.

The available data do not support the hypothesis that detritus and associated zooplankton entered the surf zone via the

account for these relationships: (1) the detritus and organisms entered the surf zone at the north end of the beach with the alongshore current, or (2) they entered the surf zone near the bottom via near-bed streaming (Reniers et al. 2004).

Modeling results suggest that the current flows from the kelp bed to the surf zone at the northern end of the beach, at the northern end of the study area (Fig. 1), feeding the alongshore current within the surf zone (Fujimura et al. 2013). Although detritus alongshore current. This hypothesis, however, cannot be conclusively tested because we did not directly sample the water in the onshore flow that fed the alongshore current in the surf zone. Even though the source of the alongshore current was offshore water carried into the surf zone, the onshore flow did not contain much offshore plankton, although it is not clear why this would be the case. The model suggests that the onshore flow likely originates in the kelp bed at the northern end of the study area. Perhaps coastal 


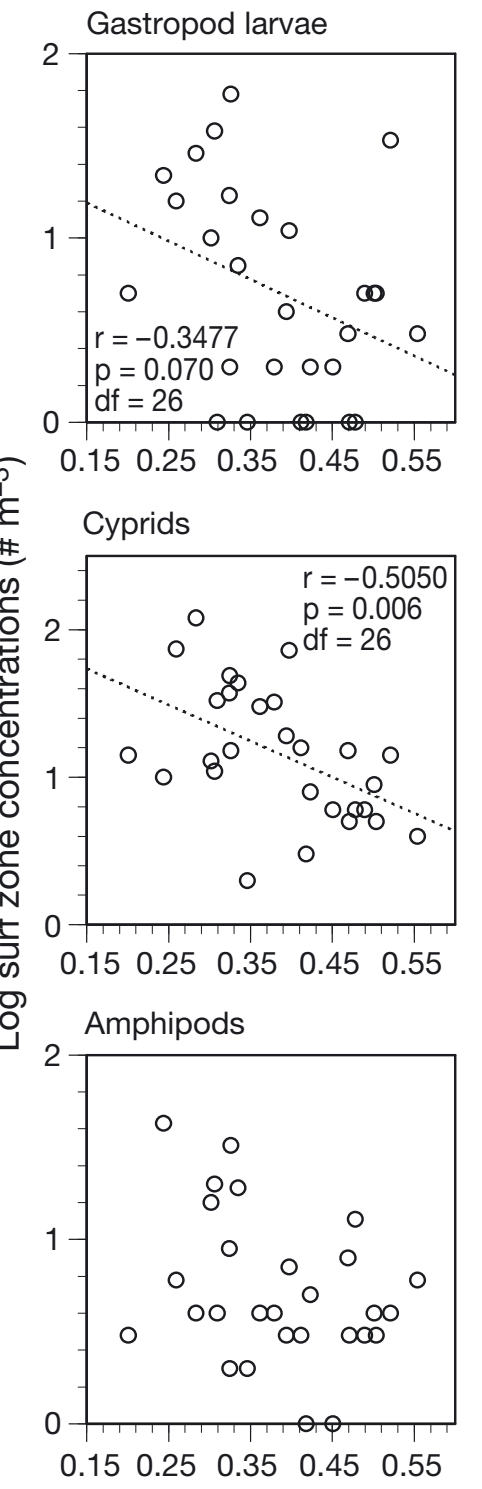

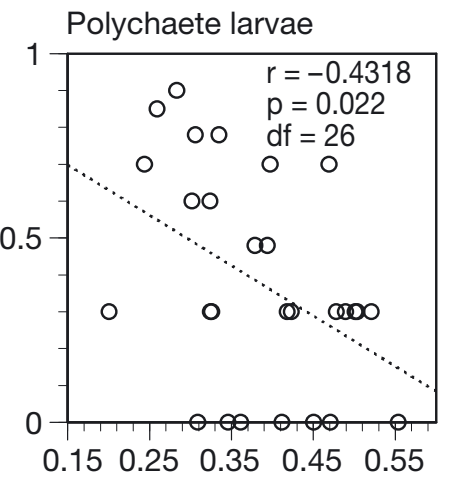
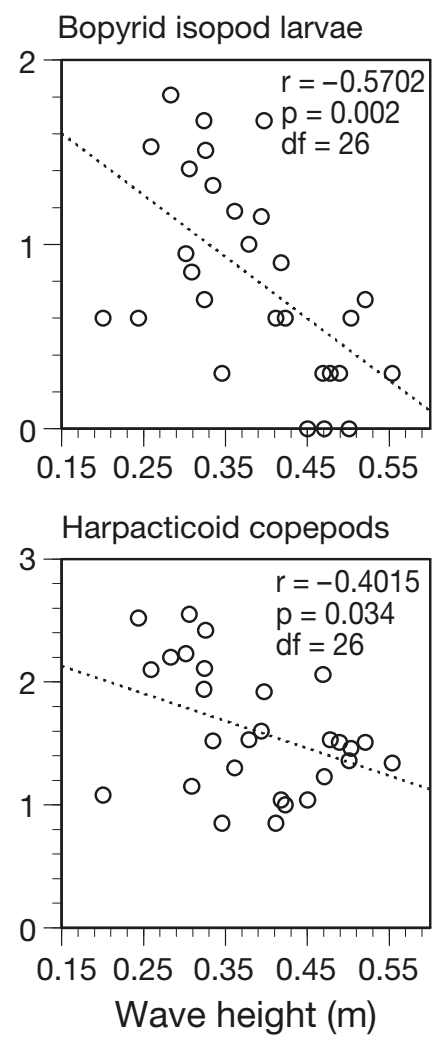

Fig. 11. Average wave height during the time samples were collected in the surf zone plotted with the log surf zone concentrations of competent meroplankters (gastropod, polychaete, cyprids, and bopyrid isopods) and organisms that may be associated with detritus (amphipods and harpacticoid copepods). The dotted line and statistics are from correlation analyses plankton are removed from the water during passage through the kelp bed; concentrations of cyprids as well as other mero- and holoplankters have been observed to decrease across a kelp bed due to predation by fish within the bed (Gaines \& Roughgarden 1987). However, we were unable to find any studies that compared the concentrations of coastal phytoplankton taxa in and out of kelp beds. Perhaps with a different shoreline configuration, offshore water feeding into an alongshore current from offshore could transport meroplankters developing in coastal waters to shore. Where such a current impinges on a rocky shoreline, one would expect to see higher settlement where the onshore flow contacts the shore, with decreasing settlement downstream in the alongshore flow.
We hypothesize that detritus, detritus-associated organisms, and competent larval invertebrates entered the surf zone via near-bed streaming. In the case of sinking material (such as detritus), concentrations should be higher near the seabed, at least during periods of low turbulence (e.g. when waves or currents are small). In the presence of waves, material at the seabed can be transported onshore within the wave boundary layer. The wave boundary layer (on the order of $\mathrm{cm}$ thick) is generated by the dissipation of wave energy at the bed, resulting in a net force in the direction of wave propagation, as outlined by Longuet-Higgins (1953). Streaming velocity increases from offshore toward the surf zone as the incident waves increase in height due to shoaling (see Fig. 12). At the outer surf zone, where 

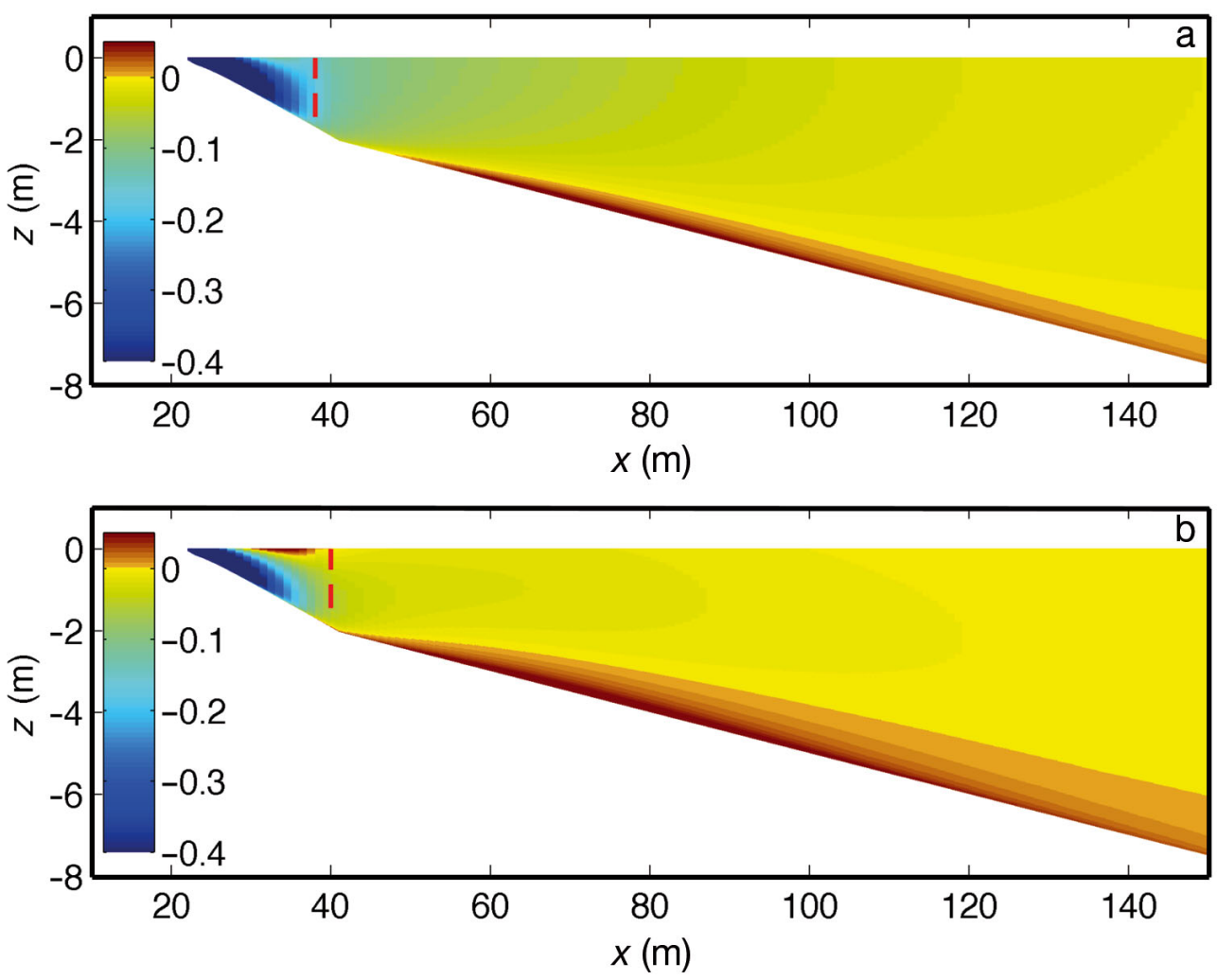

Fig. 12. (a) Mean modeled cross-shore Eulerian flow (positive onshore) at a beach similar to Carmel River State Beach (CRSB) using a 1-dimensional profile model (Reniers et al. 2004) of instrument height ( $z$ ) versus cross-shore location ( $x$ ). (b) A similar model, but including Stokes drift (Eq. 8). Cross-shore flow is driven by normally incident waves only. The vertical red dashed line indicates the outer edge of the surf zone, where waves start breaking. The undertow generated by the breaking waves within the surf zone is clearly visible (blue cloud). Note that in (a) the mean Eulerian flow in the surface layer below the trough level is offshore. Flow here is pulsed onshore with each breaking wave but offshore between: hence, when the mean is calculated, flow is weakly offshore. Including the Stokes drift (b) creates an onshore flow near the surface at the outer surf zone (compare a and b). Near-bed streaming is clearly visible (orange layer at the bottom) extending across the model domain. The streaming layer is thicker offshore and thins as the outer edge of the surf zone is approached. At the outer edge of the surf zone, cross-shore flow is slightly offshore for the Eulerian flow (a) and near zero if Stokes drift is included (b). Note that the flow here is pulsed as well, onshore with the passage of each breaking wave with offshore undertow flow between waves

waves start breaking, streaming is suppressed by the return flow compensating the wave-related mass flux, and changes into an offshore-directed near-bed velocity (Reniers et al. 2004). The crossshore distribution of streaming flow can clearly be seen in modeled currents (Fig. 12), which leads to a convergence zone of bed-material just outside of the surf zone. To get into the surf zone, this bed material must be taken up by the flow generated by breaking waves. This can happen at the shore break, where breaking waves generate strong vertical motions that essentially picks up bed material and transports it into the surf and swash zone of the beach. This is the same entrainment mechanism that affects the on- and offshore transport of fine sediments at the shore break (Reniers et al. 2013). The wave group sequencing of waves can aid in this onshore transport; during a lull in the waves, bedmaterial settles close to the narrow surf zone edge. The next set of high waves breaks further offshore, trapping the material within the surf zone and subsequently transporting it onshore. This process leads to higher concentrations within the surf zone than farther offshore, consistent with our observations.

Streaming increases with increasing wave height, and subsequently more bed material gets transported to the surf zone edge (Reniers et al. 2013). We, however, observed a negative correlation between the concentrations of surf zone detritus and associated zooplankters and wave height. With increasing wave height, wave-induced turbulence becomes more vigorous, which we hypothesize keeps detritus and associated zooplankters in suspension longer, 
such that they are transported offshore by the mean return flow above the wave boundary layer. This depletes the surf zone of these constituents (Reniers et al. 2013), resulting in a negative correlation between concentrations of surf zone detritus and associated zooplankters and incident wave height. Onshore transport occurs during periods of small waves when streaming flow is weaker. This hypothesized mechanism of surf zone entrainment of detritus works when waves are small enough that detritus and zooplankters can settle to the seabed and remain there long enough for streaming to transport them into the surf zone.

Navarrete et al. (2015) presented data suggesting that 2 species of intertidal mussels in Chile use streaming to cross the inner shelf and surf zone to settle in the intertidal. Larvae of these species settle and metamorphose offshore, but likely close to shore. They remain on the bottom for about $20 \mathrm{~d}$, during which time their shell develops and as a consequence they become dense, with sinking rates ranging from 1 to $5 \mathrm{~cm} \mathrm{~s}^{-1}$ (similar to the sinking rate of fine to medium sand). Mussel delivery to the intertidal zone was significantly correlated with wave height, but in these much denser, faster sinking organisms, delivery was higher during periods of larger waves. Morgan et al. (2009), working in central California, observed higher recruitment of mussels to moored collectors on the bottom than to those near the surface. In a laboratory experiment, Fuchs \& DiBacco (2011) observed late-stage mussel larvae swimming down in enhanced turbulence; a behavior that may direct them into near-bed streaming flow.

Near-bed streaming is a likely explanation for the delivery of both the mussels in Chile and California, and our observations of the relationship between wave height and detritus and competent meroplankton concentrations in the surf zone. Metamorphosed mussels, as relatively dense particles, sink rapidly and can remain on the bottom during more turbulent conditions. While on the bottom, Navarrete et al. (2015) hypothesized that they are transported by more energetic streaming events caused by larger waves, as is coarse sand (Reniers et al. 2013). The higher delivery during large wave events may be due to more energetic streaming currents and to the initiation of streaming further offshore during larger wave events, when mussels that had settled in deeper water would be transported toward shore. In contrast, detritus sinks about an order of magnitude slower, at about the speed of very fine sand; turbulence from larger waves may prevent it from settling to the bottom. During periods of smaller waves and weaker turbulence, we hypothesize that detritus and a variety of meroplankters can sink to the bottom where the less energetic streaming caused by smaller waves carries them into the surf zone. In both cases, streaming is hypothesized to transport meroplankters across the inner shelf and into the surf zone, leading to delivery of new recruits to the shore. Transport within near-bed streaming may take several different forms; very dense organisms might be transported as bed load, whereas swimming larvae and detritus may be carried above the bottom suspended in the flow, and metamorphosed bivalves (such as the mussels in the Chilean study) may be transported as thread drifters.

Near-bed streaming is set up by the interaction of waves with the bottom; hence, streaming should be present at all shores, and out to a depth where waves begin to 'feel' the bottom-roughly half their wave length (Lentz \& Fewings 2012). How close to shore streaming commences will vary with the wave field (Trowbridge \& Madsen 1984, Kranenburg et al. 2012, Henriquez et al. 2014) and the slope of the bottom, but it is probably often present within tens to hundreds of meters of the shore (Fig. 12). It has long been observed that as the larvae of nearshore invertebrates approach the completion of their development, many taxa exhibit behaviors that direct them toward the bottom (Thorson 1964). In addition, a variety of larval types swim down when they encounter strong turbulence (reviewed in Fuchs \& DiBacco 2011). Clearly, these behaviors would aid competent larvae developing in the plankton to locate and settle on the benthos, but these behaviors may also assist larvae in their migration to shore. Larvae that sink or swim down may enter near-bed streaming and thus be transported shoreward. Our data, along with that of Navarrete et al. (2015) and Morgan et al. (2009) suggest that competent larvae can enter the surf zone via near-bed streaming, and given the universality of the associated physics, that this transport mechanism could be exploited by larvae on all shores.

Acknowledgements. This collaborative research effort was supported by a National Science Foundation grant (NSFOCE\#092735) to A.L.S., S.G.M., J.M., and A.J.H.M.R. Field and laboratory assistance was provided by R. Cowen, C. Gon, M. Hogan, J. Noseff, E. Thornton, D. Trovillion, D. Watson, and K. Wyckoff. This is a contribution of the Oregon Institute of Marine Biology, the Bodega Marine Laboratory, the Naval Postgraduate School and Rosenstiel School of Marine and Atmospheric Science. 


\section{LITERATURE CITED}

Battjes JA (1974) Surf similarity. Coast Eng 1:466-479

Elgar S, Herbers THC, Guza RT (1994) Reflection of ocean surface gravity waves from a natural beach. J Phys Oceanogr 24:1503-1511

Elgar S, Guza RT, O'Reilly WC, Raubenheimer B, Herbers THC (2001) Wave energy and direction observed near a pier. J Waterw Port Coast Ocean Eng 127:2-6

Fuchs HL, DiBacco C (2011) Mussel larval responses to turbulence are unaltered by larval age or light conditions. Limnol Oceanogr Fluids Environ 1:120-134

Fuchs HL, Mullineaux LS, Solow AR (2004) Sinking behavior of gastropod larvae (Ilyanassa obsoleta) in turbulence. Limnol Oceanogr 49:1937-1948

Fujimura A, Reniers A, Paris C, Shanks A, MacMahan J, Morgan S (2013) Slope-dependent biophysical modeling of surf zone larval transport. In: Proc 7th Int Conf Coastal Dynamics, 24-28 Jun 2013, Arcachon, Bordeaux University, p 661-670

Gaines SD, Roughgarden J (1987) Fish in offshore kelp forests affect recruitment to intertidal barnacle populations. Science 235:479-481

Hasselmann K (1970) Wave-driven inertial oscillations. Geophys Fluid Dyn 1:463-502

Hendrickson J, MacMahan J (2009) Diurnal sea breeze effects on inner-shelf cross-shore exchange. Cont Shelf Res 29:2195-2206

Henriquez M, Reniers AJHM, Ruessink BG, Stive MJF (2014) PIV measurements of the bottom boundary layer under nonlinear surface waves. Coast Eng 94:33-46

Kranenburg WM, Ribberink JS, Uittenbogaard RE, Hulscher SJMH (2012) Net currents in the wave bottom boundary layer: on waveshape streaming and progressive wave streaming. J Geophys Res 117, F03005, doi:10.1029/2011 JF002070

> Lentz SJ, Fewings MR (2012) Wind- and wave-driven innershelf circulation. Annu Rev Mar Sci 4:317-343

Lentz SJ, Fewings M, Howd P, Fredericks J, Hathaway K (2008) Observations and a model of undertow over the inner continental shelf. J Phys Oceanogr 38:2341-2357

Longuet-Higgins MS (1953) Mass transport in water waves. Philos Trans R Soc Lond A 245:535-581

MacMahan JH, Stanton T, Thornton EB, Reniers AJHM (2005) RIPEX: observations of a rip current system. Mar Geol 218:113-134

MacMahan JH, Brown J, Brown J, Thornton EB and others (2010) Mean Lagrangian flow behavior on an open coast rip-channeled beach: a new perspective. Mar Geol 268: $1-15$

Miche R (1951) Le pouvoir reflechissant des ouvrages maritimes exposes a l'action de la houle. Ann Ponts Chaussees 121:285-319

Miles JR, Russell PE (2004) Dynamics of a reflective beach with a low tide terrace. Cont Shelf Res 24:1219-1247

Monismith SG, Cowen EA, Nepf HM, Magnaudet J, Thais L (2007) Laboratory observations of mean flows under surface gravity waves. J Fluid Mech 573:131-147

Morgan SG, Fisher JL, Mace AJ (2009) Larval recruitment in a region of strong, persistent upwelling and recruitment limitation. Mar Ecol Prog Ser 394:79-99

Editorial responsibility: Romuald Lipcius,

Gloucester Point, Virginia, USA
Navarrete SA, Largier JL, Vera G, Tapia FJ and others (2015) Tumbling under the surf: wave-modulated settlement of intertidal mussels and the continuous settlement-relocation model. Mar Ecol Prog Ser 520:101-121

> Reniers AJHM, Thornton EB, Stanton TP, Roelvink JA (2004) Vertical flow structure during Sandy Duck: observations and modeling. Coast Eng 51:237-260

Reniers A, MacMahan JH, Thornton EB, Stanton TP and others (2009) Surfzone retention on a rip channeled beach. J Geophys Res 114, C10010, doi:10.1029/2008JC 005153

> Reniers AJHM, Gallagher EL, MacMahan JH, Brown JA and others (2013) Observations and modeling of steepbeach grain-size variability. J Geophys Res 118:577-591

> Sénéchal N, Abadie S, Gallagher E, MacMahan JHM and others (2011) The ECORS-Truc Vert'08 nearshore field experiment: presentation of a three-dimensional morphologic system in a macro-tidal environment during consecutive extreme storm conditions. Ocean Dyn 61(Suppl 1):2073-2098

Seymour RJ (1989) Nearshore sediment transport. Plenum Press, New York, NY

Shanks AL (ed) (2001) An identification guide to the larval marine invertebrates of the Pacific Northwest. Oregon State University Press, Corvallis, OR

Shanks AL, Shearman RK (2009) Paradigm lost? Cross-shelf distributions of intertidal invertebrate larvae were unaffected by upwelling or downwelling. Mar Ecol Prog Ser 385:189-204

Shanks AL, Morgan SG, MacMahan J, Reniers AJHM (2010) Surf zone physical and morphological regime as determinants of temporal and spatial variation in larval recruitment. J Exp Mar Biol Ecol 392:140-150

Shanks AL, Morgan SG, MacMahan J, Reniers AJHM and others (2014) Onshore transport of plankton by internal tides and upwelling-relaxation events. Mar Ecol Prog Ser 502:39-51

> Sheremet A, Guza RT, Elgar S, Herbers THC (2002) Observations of nearshore infragravity waves: seaward and shoreward propagating components. J Geophys Res 107 , C83095, doi:10.1029/2001JC000970

Smith JA (2006) Wave groups, Stokes drift and Eulerian response. J Phys Oceanogr 36:1381-1403

Stokes GG (1847) On the theory of oscillatory waves. Trans Camb Philos Soc 8:441-455

Tatavarti RSVN, Huntley DA, Bowen AJ (1988) Incoming and outgoing wave interactions on beaches. Proc 21st Conf Coast Eng, New York, NY 1:136-150

Thornton EB, Guza RT (1983) Transformation of wave height distribution. J Geophys Res 88:5925-5938

Thorson G (1964) Light as an ecological factor in the dispersal and settlement of larvae of marine bottom invertebrates. Ophelia 1:167-208

Trowbridge J, Madsen OS (1984) Turbulent wave boundary layers 2. Second-order theory and mass transport. J Geophys Res 89:7999-8007

Wright LD, Short AD (1984) Morphodynamic variability of surf zones and beaches: a synthesis. Mar Geol 56: 93-118

> Xu Z, Bowen AJ (1994) Wave- and wind-driven flow in water of finite depth. J Phys Oceanogr 24:1850-1866 